\title{
A Research On Various PV Arrays Manufacturing Data For Power Comparison And Optimization Through Extremum Seeking Technique
}

Aqeel Ahmed ${ }^{1}$, Mazhar Hussain Baloch ${ }^{1}$, Baqir Ali Mirjat ${ }^{1}$, Ali Asghar Memon², Touqeer Ahmed Jumani ${ }^{1}$

\begin{abstract}
:
The increasing environmental repercussions and depletion of nonrenewable energy resources have cautioned and enabled researchers to incorporate renewable energy systems. Amongst the renewable energy resources, the solar energy system has been utilized in most parts of the world due to cheaper, reliable, robust and sustainable energy resource than other resources. The Maximum Power Point Tracking (MPPT) techniques are used for increasing the power output of the PV array. The Perturb and Observe (P\&O) technique is a widely used MPPT technique due to its higher efficiency and ease of implementation. The proposed "Perturb and Observe (P\&O)" MPPT technique is incorporated through MATLAB Simulation software on PV arrays of various companies. The results are then compared through comparative analysis and optimum results are recommended for the manufacturing companies.
\end{abstract}

Keywords: Perturb and observe; Maximum power point tracking; Photovoltaic; MATLAB; simulation; comparative analysis; renewable energy; power \& efficiency

\section{Introduction}

The vast usage of non-renewable energy resources around the world has implicated hazardous effects on the environment and become a chief cause of the depletion of fossil fuels [1]. The growing environmental impacts and depletion of conventional energy resources shifted the focus of many countries from conventional energy resources to renewable energy resources. The conventional energy resources made it possible to reduce the dependency on non-renewable energy resources and became a considerable cause for the economic growth of the world [2]. In renewable energy resource, Solar energy is free of pollution, robust in its operation, with a low maintenance cost required, considerable useful life and is widely available with comparable efficiency and reliability [3-4]. Many applications such as thermal power production, pumping system, electric power generation, battery charging stations and electric vehicles employ solar energy system for their operation [5]. PV cells are composed of different semiconductor materials and when posed to the sunlight become electrically conductive and transform a part of solar irradiance directly into electrical energy [6]. Solar arrays are made by interconnecting PV modules in combined series and parallel, whose characteristics are the same as that of a single module [7]. The V-I characteristics of PV cell are non-linear and depend upon the intensity of sunlight and its temperature, due to the continuous varying atmospheric conditions, the efficiency of solar modules changes [8-9]. Several MPPT techniques have

${ }^{1}$ Electrical Engineering Department, MUET SZAB Campus Khairpur, Pakistan

${ }^{2}$ Electrical Engineering Department, MUET Jamshoro, Pakistan

Corresponding Author: aqeelahmed13el34@gmail.com 
Aqeel Ahmed (et al.), A Research On Various PV Arrays Manufacturing Data For Power Comparison And Optimization Through Extremum Seeking Technique (pp. $59-66)$

been utilized for improving the efficiency and reliability of PV modules such as Perturb \& Observe technique, Fuzzy logic control technique, Incremental Conductance technique etc. The Perturb \& Observe (P\&O) technique offers greater efficiency and reliability with robust in construction and simple in operation [10].

The $\mathrm{P} \& \mathrm{O}$ technique is widely used to improve the performance and efficiency of PV module using the MPPT algorithm. This technique utilizes a feedback approach in which output power is continuously compared with the previous perturbation cycle [11]. It follows the previous value, if the present output power is greater than the previous value then its power will remain in the same direction while its direction will be reversed if the current value of output power is lesser than the previous value [12]. The authors J. Ahmed et al., researched to enhance the efficiency of the existing P\&O MPPT system by controlling steady-state fluctuations and proper tracking of direction [13]. The efficiency was improved by mitigating steady-state fluctuations and removing the possibility of divergence from the MPP locus [14]. MPPT technique for extraction of optimum power from PV module by locating the operating point at maximum level [15]. These authors have also set a classification of various MPPT techniques based on variables and algorithms which are important for selecting a suitable technique for the PV modules [16-17].

The above papers have extensively discussed and compared the various MPPT techniques but none of them has compared the manufactured PV models, so this paper compares the voltage and power output of various PV models of different companies and validates the best model among them by using P\&O MPPT technique.

\section{Proposed Model Description}

A model was developed in the MATLAB software in which two PV arrays each of 100 $\mathrm{kW}$ are used at a constant sun irradiance of $1000 \mathrm{~W} / \mathrm{m}^{2}$. The output voltage of each PV

Sukkur IBA Journal of Emerging Technologies - SJET | Vol. 4 No. 1 January - June 2021

array was amplified to $500 \mathrm{~V}_{\mathrm{DC}}$ by utilizing a boost converter.

Two MPPT controllers based on (P\&O) technique were incorporated in the boost converters which amplify the output of PV arrays to $500 \mathrm{~V}_{\mathrm{DC}}$ employing a function block that generates programmable $\mathrm{C}$ code. These boost converters are then connected to a single three phase voltage source converter (VSC) which changes the incoming voltage of $500 \mathrm{~V}$ $\mathrm{DC}$ to $260 \mathrm{~V}$ and maintains the unity power factor. There are two control loops in a system: an outer control loop that maintains the DC voltage to $+/-260 \mathrm{~V}$ and an inner control loop that maintains active current (ID) and reactive current (IQ). IQ is used for maintaining the unity power factor.

Three modulating reference signals utilized by a three-level pulse generator are produced by changing active and reactive voltage outputs of the current controller.

From $\mathrm{t}=0 \mathrm{sec}$ to $\mathrm{t}=0.05 \mathrm{sec}$ of simulation, pulses to VSC and Boost are not functionalized and the open-circuit voltage of PV models has appeared at output terminals, that charges the capacitors above $500 \mathrm{~V}$ DC after passing through diode rectifiers.

At $\mathrm{t}=0.05 \mathrm{sec}$ of simulation, the VSC and boost converters are included in the simulation. The duty cycle of boost converters is fixed at $\mathrm{D}=0.5$ and sun irradiance is set to $1000 \mathrm{~W} / \mathrm{m}^{2}$. Steadystate is reached at $0.25 \mathrm{sec}$. The resulting PV voltage is given by (1):

$$
V_{p h}=(1-D) V_{d c}
$$

Therefore,

$$
V_{p h}=(1-0.5) * 500=250 \mathrm{~V}
$$

At $\mathrm{t}=0.4 \mathrm{sec}$ of simulation, MPPT is enabled. The MPPT controller starts controlling PV voltage by adapting the duty cycle for extracting maximum power. At 0.485 duty cycle, the maximum power of $100.7 \mathrm{~kW}$ is achieved.

From $\mathrm{t}=0.7 \mathrm{sec}$ to $\mathrm{t}=1.2 \mathrm{sec}$ of simulation, irradiance is reduced from $1000 \mathrm{~W} / \mathrm{m}^{2}$ to 250 $\mathrm{W} / \mathrm{m}^{2}$ and at $\mathrm{t}=1.2 \mathrm{sec}$, when irradiance has reduced to $250 \mathrm{~W} / \mathrm{m}^{2}$, duty cycle is 0.485 . 
Aqeel Ahmed (et al.), A Research On Various PV Arrays Manufacturing Data For Power Comparison And Optimization Through Extremum Seeking Technique

Equivalent $\mathrm{PV}$ voltage and power are $\mathrm{V}_{\text {mean }}=$ $255 \mathrm{~V}$ and $\mathrm{P}_{\text {mean }}=22.6 \mathrm{~kW}$ respectively.

From $\mathrm{t}=1.5 \mathrm{sec}$ to $3 \mathrm{sec}$, several irradiances are applied for elucidating the better performance of the MPPT controller and the unity power factor was observed on the scope grid

The controlling system utilizes a discrete time of 100 microseconds for voltage and current controllers and the harmonics produced by the voltage source converter is filtered by utilizing the capacitor bank of 20 $\mathrm{kVAR}$. Furthermore, the terminal voltage of VSC $(260 \mathrm{~V})$ is stepped up to $25 \mathrm{kV}$ by using a $200 \mathrm{kVA}$ three-phase coupling transformer. The $25 \mathrm{kV}$ output voltage of a stepped-up transformer is then transmitted to a utility grid of $25 \mathrm{kV}$ distribution feeder as depicted in Fig. 1.

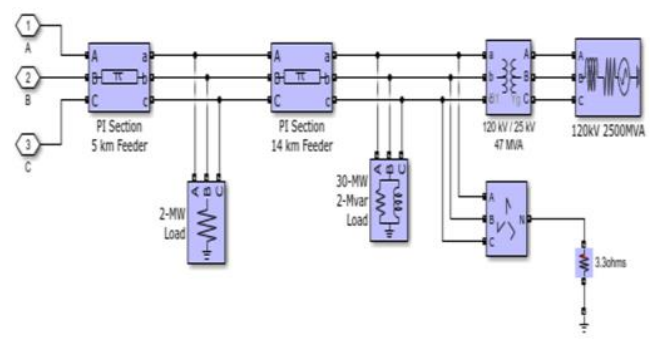

Fig. 1. Utility Grid System

\section{Results and Discussion}

The data of eight different PV models were simulated under the Standard Temperature and Pressure (STP) condition and at a constant solar irradiance of $1000 \mathrm{~W} / \mathrm{m}^{2}$.

The comparison of two PV models was done at a time and one particular PV model was taken as a reference model (Canadian Solar CS5P-220M). The complete data of simulated models are given in Table 1 .

TABLE I. Manufactured models data at STP

\begin{tabular}{|c|c|c|c|}
\hline Sr. & Model & $\begin{array}{c}\text { Input } \\
\text { Irradiance } \\
\left(\mathbf{W} / \mathbf{m}^{2}\right)\end{array}$ & $\begin{array}{c}\text { Temp. } \\
\left({ }^{\mathbf{0}} \mathbf{C}\right)\end{array}$ \\
\hline 1 & $\begin{array}{c}\text { Canadian Solar } \\
\text { CS5P-220M }\end{array}$ & 100 & 25 \\
\hline 2 & $\begin{array}{c}\text { First Solar FS- } \\
272\end{array}$ & 100 & 25 \\
\hline 3 & $\begin{array}{c}\text { Sanyo HIP-225 } \\
\text { HDE1 }\end{array}$ & 100 & 25 \\
\hline 4 & $\begin{array}{c}\text { Sun Power } \\
\text { SPR-305-WHT }\end{array}$ & 100 & 25 \\
\hline 5 & $\begin{array}{c}\text { Sun Tech } \\
\text { STP270S-24 }\end{array}$ & 100 & 25 \\
\hline 6 & $\begin{array}{c}\text { Mitsubishi PV- } \\
\text { UD190MFS }\end{array}$ & 100 & 25 \\
\hline 7 & $\begin{array}{c}\text { Kyocera } \\
\text { KD205GX-LP }\end{array}$ & 100 & 25 \\
\hline 8 & $\begin{array}{c}\text { BP Solar } \\
\text { SX3190 }\end{array}$ & 100 & 25 \\
\hline
\end{tabular}

The graph of constant irradiance (1000 $\mathrm{W} / \mathrm{m}^{2}$ ) is shown in Figure 2. The irradiance for each PV model was kept the same but varies to time so that the output power and voltage can be analyzed and compared simultaneously.

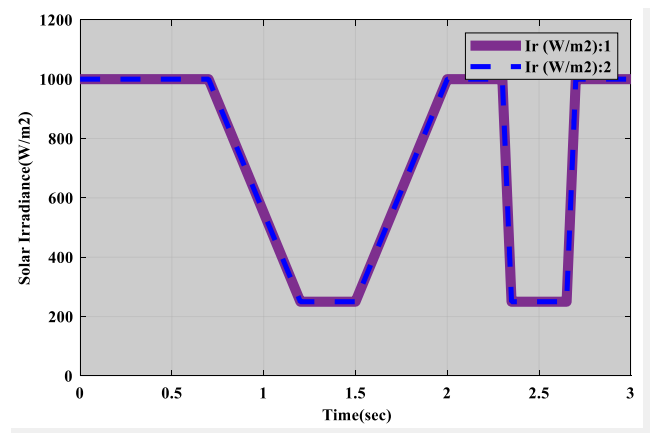

Fig. 2. Solar Irradiance $\left(\mathrm{W} / \mathrm{m}^{2}\right)$

The Canadian Solar CS5P-220M (Reference model) is simulated with First Solar FS-272 and simulated voltage and power graphs are shown in Fig. 3 and Fig. 4 respectively. It is depicted in Fig. 3 that the output voltage of First Solar FS-272 fluctuates initially and gets damped after some time. It is also observed that CS5P-220M is more sensitive to FS-272 with respect to varying irradiance. Despite irradiance sensitivity, the output voltage of FS-272 is more than the 
Aqeel Ahmed (et al.), A Research On Various PV Arrays Manufacturing Data For Power Comparison And Optimization Through Extremum Seeking Technique

CS5P-220M. The power output graph of Fig. 4 shows that the output power characteristics of CS5P-220M are far better than the FS-272 due to sensitivity and current capacity.

The Canadian Solar CS5P-220M (Reference model) is simulated with Sanyo HIP-225 HDE1. Simulated voltage and power graphs are shown in Fig. 5 and Fig. 6 respectively. It is clearly shown in Fig. 5, the output voltage of Sanyo HIP-225 HDE1 is impulsive initially but gets damped after some time and the output voltage of Sanyo HIP-225 HDE1 is more than the Canadian solar as shown in Fig.8. The power output graph in Fig. 6 shows that the output power characteristic of Sanyo HIP-225 HDE1 is better than Canadian Solar CS5P-220M.

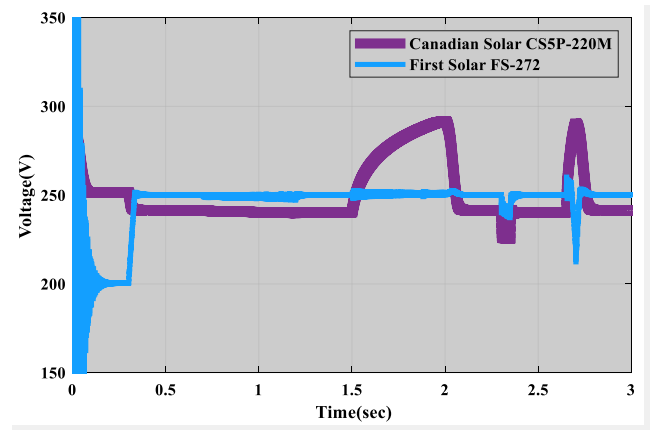

Fig. 3. The output voltage of CS5P-220M and FS-272

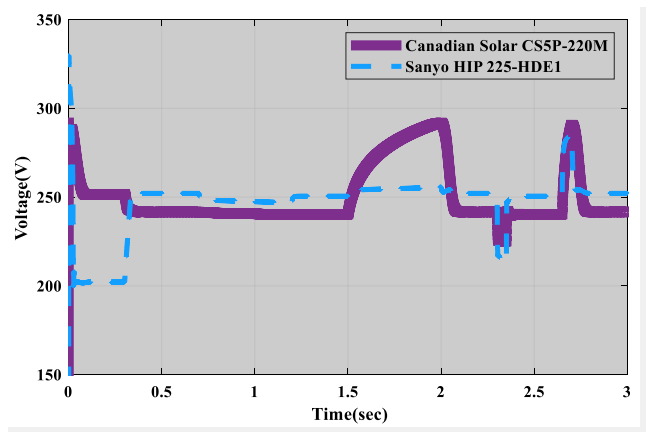

Fig. 5. The output voltage of CS5P-220M and FS-272

The Canadian Solar CS5P-220M (Reference model) is simulated with Sun Power SPR-305-WHT and simulated voltage and power graphs are shown in Fig. 7 and Fig. 8 respectively. In Fig. 7 the output voltage of First Solar FS-272 is largely fluctuating initially but gets damped after some time. So, Sun Power SPR-305-WHT is more sensitive to Canadian Solar CS5P-220M due to varying irradiance. Despite irradiance sensitivity, the output voltage of Sun Power SPR-305-WHT is more than the Canadian solar CS5P-220M as shown in Fig.7. The power output graph in Fig. 8 shows that the output power characteristics of Sun Power SPR-305-WHT are quite better than Canadian solar CS5P-220M.

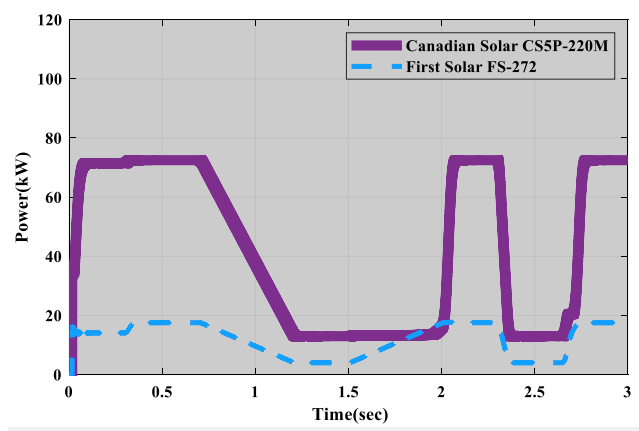

Fig. 4. The output power of CS5P-220M and FS-272

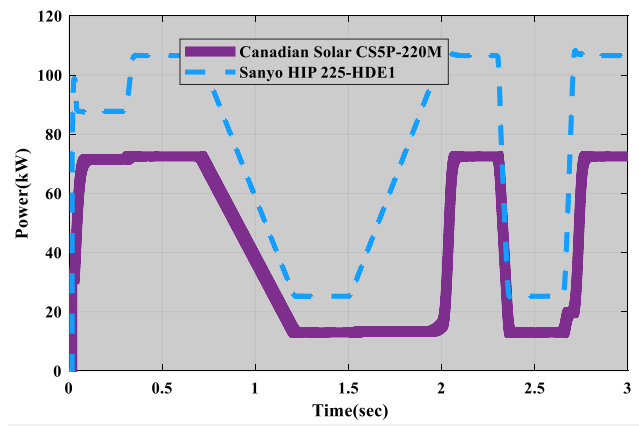

Fig. 6. The output power of CS5P-220M and FS-272 
Aqeel Ahmed (et al.), A Research On Various PV Arrays Manufacturing Data For Power Comparison And Optimization Through Extremum Seeking Technique

(pp. 59 - 66)

The Canadian Solar CS5P-220M

(Reference model) is simulated with Suntech STP270S-24 and simulated voltage and power graphs are shown in Fig. 9 and Fig. 10 respectively. It is clearly set out in Fig. 9 that the output voltage of Sun Tech STP270S-24 is highly impulsive at the initial stage but gets damped after some time. The output voltage of Sun Tech STP270S-24 is considerably more than Canadian solar as shown in Fig. 9. The power output graph in Fig. 10 shows that the output power characteristics of Sun Tech STP270S-24 are far better than Canadian Solar CS5P-220M.

The Canadian Solar CS5P-220M (Reference model) is simulated with Mitsubishi PV-UD190MFS and simulated voltage and power graphs are shown in Fig. 11 and Fig. 12 respectively. It is clearly shown in

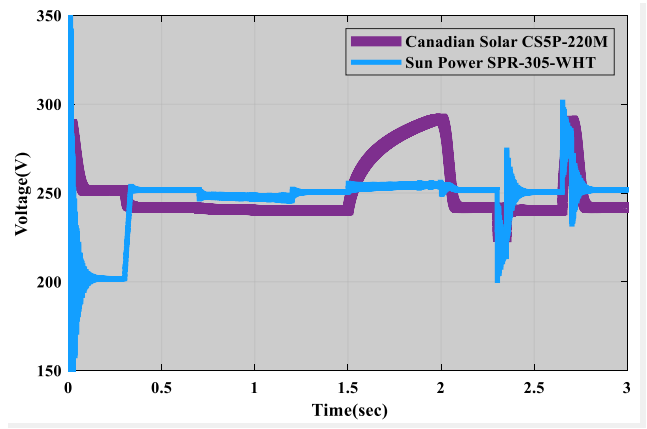

Fig. 7. The output voltage of CS5P-220M and SPR-305

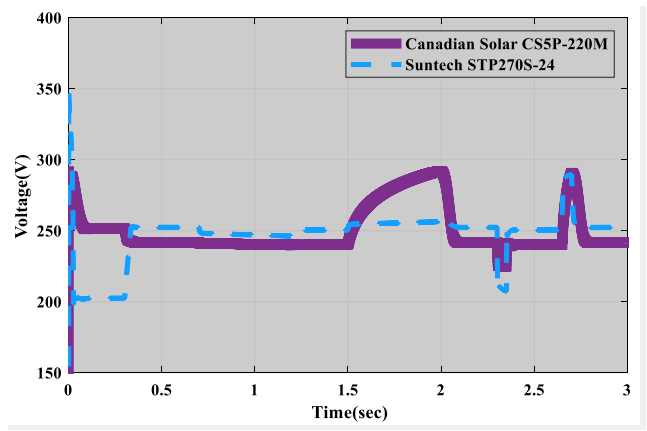

Fig. 9. The output voltage of CS5P-220M and Suntech STP270S-24
Fig. 11 that the output voltage of Canadian Solar CS5P-220M is better and is observed that both PV models have adaptive characteristics to varying irradiance. The power output graph in Fig. 12 shows that the output power characteristics of Mitsubishi PVUD190MFS are superior to Canadian Solar CS5P-220M. The Canadian Solar CS5P-220M (Reference model) is simulated with Kyocera KD205GX-LP and simulated voltage and power graphs are shown in Fig. 13 and Fig. 14 respectively. It is shown in Fig. 13 that the output voltage of Canadian Solar CS5P-220M is better and is analyzed that both PV models have fairer characteristics to varying irradiance. The power output graph in Fig. 14 shows that the output power characteristics of Kyocera KD205GX-LP are better than Canadian Solar CS5P-220M.

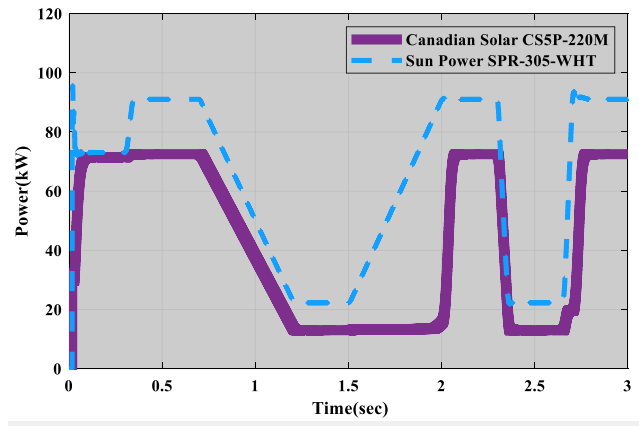

Fig. 8. The output power of CS5P-220M and SPR-305

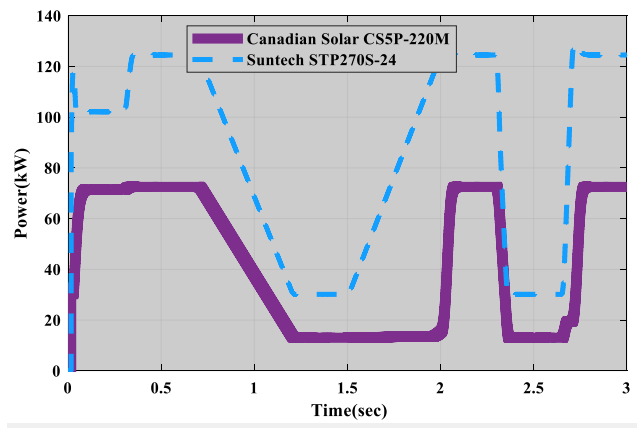

Fig. 10. Output power of CS5P-220M and Suntech STP270S-24 
Aqeel Ahmed (et al.), A Research On Various PV Arrays Manufacturing Data For Power Comparison And Optimization Through Extremum Seeking Technique

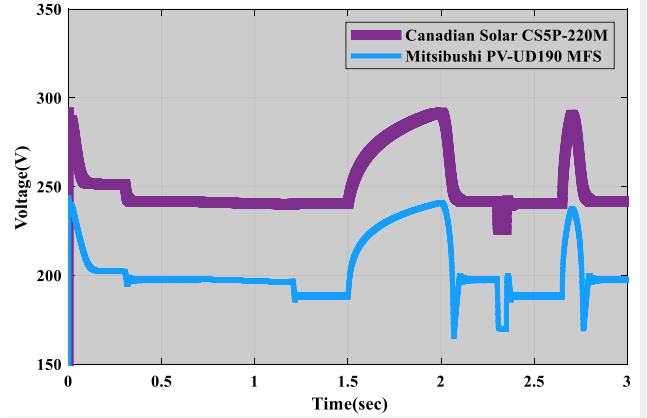

Fig. 11. The output voltage of CS5P-220M and Mitsubishi PV-UD190MFS

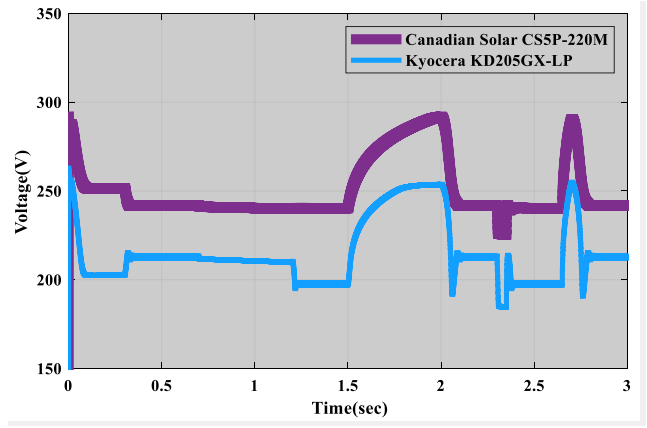

Fig. 13. The output voltage of CS5P-220M and Kyocera KD205GX-LP

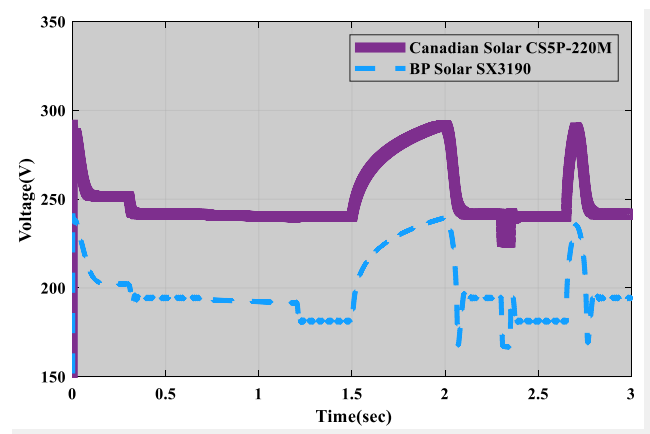

Fig. 15. The output voltage of CS5P-220M and BP Solar SX3190

The Canadian Solar CS5P-220M (Reference model) is simulated with BP Solar SX3190 and simulated voltage and power graphs are shown in Fig. 15 and Fig. 16

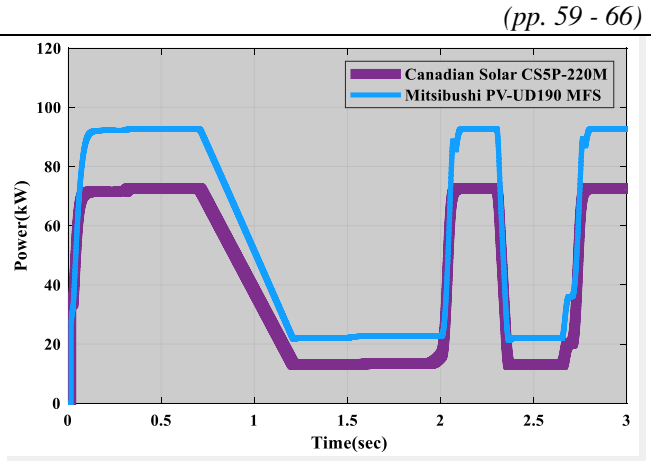

Fig. 12. The output power of CS5P-220M and Mitsubishi PV-UD190MFS

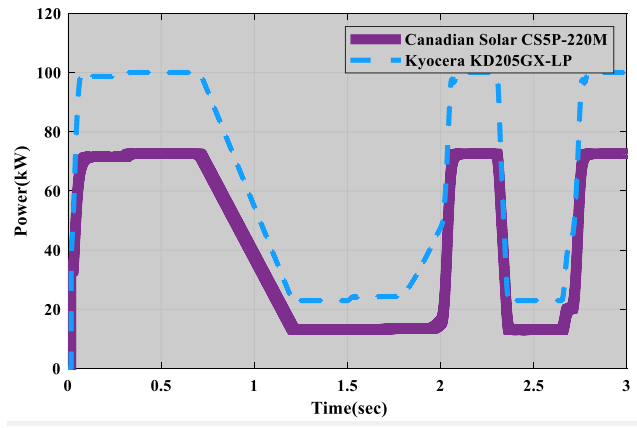

Fig. 14. The output power of CS5P-220M and Kyocera KD205GX-LP

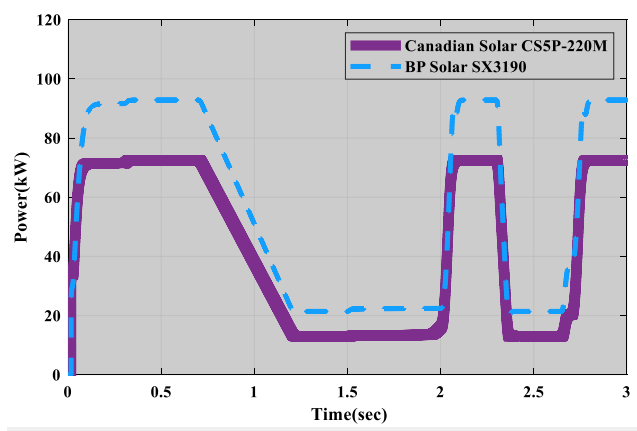

Fig. 16. The output power of CS5P-220M and BP Solar SX3190

respectively. It is cleared from Fig. 15 that the output voltage of Canadian Solar CS5P-220M is more than BP Solar SX3190 with respect to similar sun irradiance. The power output graph 
Aqeel Ahmed (et al.), A Research On Various PV Arrays Manufacturing Data For Power Comparison And Optimization Through Extremum Seeking Technique

in Fig. 16 depicts that both PV models have common varying nature and BP Solar SX3190 has far better power output than Canadian Solar CS5P-220M. The cumulative chart showing output voltage and power of all simulated PV models are shown in Fig. 17 and Fig. 18, respectively. After analyzing and comparing all simulated PV models voltage profiles, Kyocera KD205GX-LP showed the

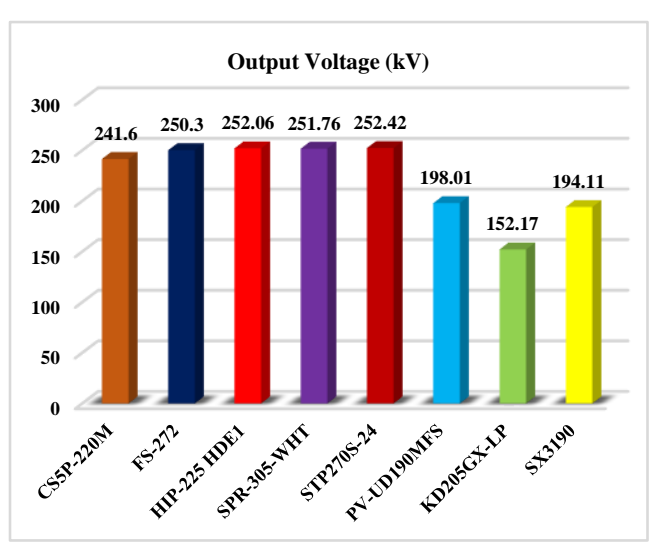

Fig. 17. Cumulative chart of the output voltage of all simulated PV models

\section{Conclusion}

The model was developed in the Matlab software for simulating the PV models of different manufacturing companies at constant solar irradiance and Standard Temperature and Pressure (STP) conditions.

* The output voltage of simulated manufactured models was amplified by boost converter and remained persistent irrespective of varying atmospheric conditions by using the (P\&O) MPPT technique.

* The harmonics produced by power semiconductor devices in VSC were mitigated by utilizing a reactive power compensator, thus unity power factor was maintained at the output.

* The output voltage and power of each manufactured model were analyzed, and it was concluded that the voltage lowest voltage output while Sun Tech STP270S-24 possessed the highest output voltage profile among all simulated PV models. And it is also observed from output power graphs of simulated PV models that First Solar FS-272 showed the lowest power output and Suntech STP270S-24 proved to be a PV model with the highest power output among all simulated PV models.

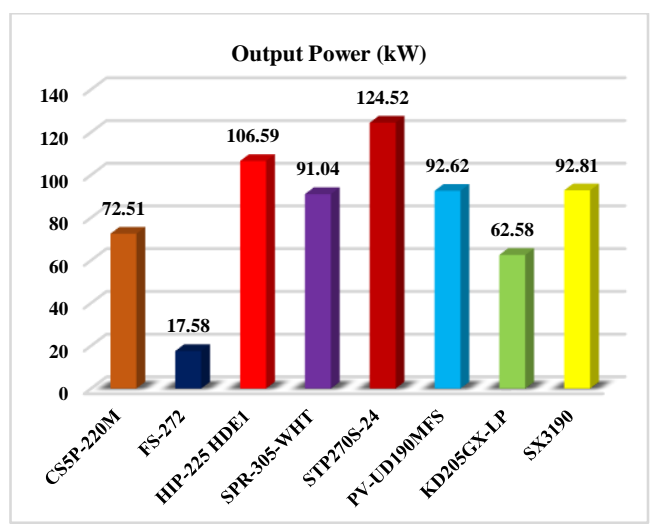

Fig. 18. Cumulative chart of the output power of all simulated PV models

and power profiles of "SUNTECH SPR-400-WHT" are the most efficient among all simulated manufactured models.

\section{AUTHOR CONTRIBUTION}

All authors contributed equally.

\section{Data Availability Statement}

The datasets generated during and/or analyzed during the current study are available from the corresponding author on reasonable request.

\section{CONFLICT OF INTEREST}

The authors declare no conflict of interest.

\section{ACKNOWLEDGMENT}

The authors are grateful to Mehran University of Engineering \& Technology Jamshoro and MUET Shaheed Zulfiqar Ali 
Aqeel Ahmed (et al.), A Research On Various PV Arrays Manufacturing Data For Power Comparison And Optimization Through Extremum Seeking Technique (pp. 59 - 66)

Bhutto Campus Khairpur Mir's for their support regarding research.

\section{REFERENCES}

[1] Ali, A., Almutairi, K., Malik, M. Z., Irshad, K., Tirth, V., Algarni, S., Zahir, M., Islam, S., Shafiullah, M., \& Shukla, N. K., "Review of online and soft computing maximum power point tracking techniques under non-uniform solar irradiation conditions," Energies, 13(12), 3256, 2020.

[2] Ali, A., Almutairi, K., Padmanaban, S., Tirth, V., Algarni, S., Irshad, K., Islam, S., Zahir, M. H., Shafiullah, M., \& Malik, M. Z., "Investigation of MPPT techniques under uniform and non-uniform solar irradiation, condition-a retrospection," IEEE Access, 8, 127368-127392, 2020.

[3] Li, H., Peng, J., Liu, W., Huang, Z., \& Lin, K.C., "A Newton-based extremum seeking MPPT method for photovoltaic systems with stochastic perturbations," International Journal of Photoenergy, 2014.

[4] Malik, M. Z., Baloch, M. H., Gul, M., Kaloi, G. S., Chauhdary, S. T., \& Memon, A. A., "A research on conventional and modern algorithms for maximum power extraction from wind energy conversion system: a review," Environmental Science and Pollution Research, 1-16, 2020.

[5] Khan, M. J., \& Mathew, L., "Different kinds of maximum power point tracking control method for photovoltaic systems: a review," Archives of Computational Methods in Engineering, 24(4), 855-867, 2017.

[6] Moura, S., "A switched extremum seeking approach to maximum power point tracking in photovoltaic systems," Grid Integration of Alternative Energy Sources, 3-498, 2009.

[7] Ezinwanne, O., Zhongwen, F., \& Zhijun, L., "Energy performance and cost comparison of MPPT techniques for photovoltaics and other applications," Energy Procedia, 107, 297-303, 2017.

[8] Houssamo, I., Locment, F., \& Sechilariu, M., "Maximum power tracking for photovoltaic power system: Development and experimental comparison of two algorithms," Renewable Energy, 35(10), 2381-2387, 2010.

[9] Mohamed, S. A., \& Abd El Sattar, M., "A comparative study of $\mathrm{P} \& \mathrm{O}$ and INC maximum power point tracking techniques for gridconnected PV systems," SN Applied Sciences, 1(2), 174, 2019.

[10] Kebir, A., Woodward, L., \& Akhrif, O., "Extremum-seeking control with adaptive excitation: Application to a photovoltaic system," IEEE Transactions on Industrial Electronics, 65(3), 2507-2517, 2017.

[11] Johnson, K. E., \& Fritsch, G, "Assessment of extremum seeking control for wind farm energy production," Wind Engineering, 36(6), 701-715, 2012.

[12] Neçaibia, A., Ladaci, S., Charef, A., \& Loiseau, J. J, "Fractional order extremum seeking approach for maximum power point tracking of photovoltaic panels," Frontiers in Energy, 9(1), 43-53, 2015.

[13] Marjanović, A., Krstić, M., Đurović, Ž., \& Kovačević, B., "Control of thermal power plant combustion distribution using extremum seeking," IEEE Transactions on Control Systems Technology, 25(5), 1670-1682, 2016.

[14] Mohamed, K. A., Zakareya, M., Youssef, K. H., \& Khater, H. A., "Improved perturb and observe maximum peak power tracking for solar satellite systems," IOP Conference Series: Materials Science and Engineering, 610(1), 12091, 2019.

[15] Moura, S. J., \& Chang, Y. A., "Lyapunovbased switched extremum seeking for photovoltaic power maximization" Control Engineering Practice, 21(7), 971-980, 2013.

[16] Brunton, S. L., Rowley, C. W., Kulkarni, S. R., \& Clarkson, C., "Maximum power point tracking for photovoltaic optimization using ripple-based extremum seeking control," IEEE Transactions on Power Electronics, 25(10), 2531-2540, 2010.

[17] Purnama, I., Lo, Y.-K., \& Chiu, H.-J, "A fuzzy control maximum power point tracking photovoltaic system," IEEE International Conference on Fuzzy Systems (FUZZ-IEEE 2011), 2432-2439, 2011. 